\title{
- Avaliação laboratorial do fluido peritoneal em modelos experimentais utilizados para indução de reação inflamatória intra-abdominal em equiinos
}

- Laboratory evaluation of peritoneal fluid in experimental models used to induce intra-abdominal inflammatory reaction in equines

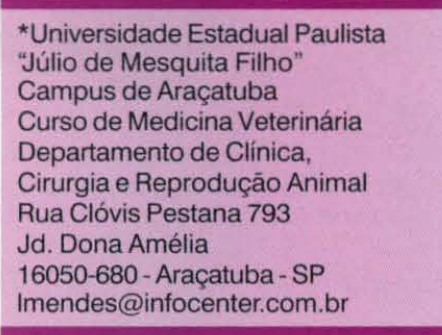

* Universidade Estadual Paulista

Júlio de Mesquita Fino"

Curso de Medicina Veterinária Departamento de Clínica,

Cirurgia e Reproduçāo Animal

Rua Clovis Pestana 793

16050-680 - Araçatuba - SP

Imendes@infocenter.com.br

* LuizCláudio Nogueira Mendes ${ }^{1}$-CRMV-SP no6112

Juliana Regina Peiró ${ }^{1}$-CRMV-SP n 7702

Luiz Carlos Marques ${ }^{2}$-CRMV-SP ñ2438

Alexandre Secorun Borges ${ }^{1}$-CRMV-SP ${ }^{\circ} 6564$

Professor Assistente do Departamento de Clínica, Cirurgia e Reprodução Animal FO - Unesp - Araçatuba

Professor Adjunto do Departamento de Clínica e Cirurgia Veterinária - FCAV - Unesp - Jaboticabal

\section{RESUMO}

Este artigo traz uma revisão da anatomia e funções do peritônio, da fisiopatologia da injúria peritoneal, avaliação do fluido peritoneal normal e compara esses parâmetros aos valores obtidos em modelos experimentais, desenvolvidos no Brasil, com o objetivo de se estudar vários aspectos da peritonite nos eqüinos, principalmente aqueles relacionados às complicações clínicas e/ou cirúrgicas da síndrome cólica. Discute, ainda, os dados obtidos na análise do líquido peritoneal, como celularidade, métodos bioquímicos, anatomopatológicos, além da quantificação de citocinas.

Palavras-chave: peritonite experimental, eqüinos, líquido peritoneal, peritônio, endotoxemia.

\section{Introdução}

\section{Estruturas e funções do peritônio}

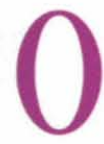
peritônio é uma camada de tecido que recobre todas as estruturas dentro da cavidade abdominal, sendo formado pelo peritônio parietal, que reveste a parede abdominal e o diafragma, e pelo peritônio visceral, que é uma continuação da porção parietal e recobre os dois lados do omento e forma a superfície serosa do intestino. O espaço entre os peritônios visceral e parietal é denominado cavidade peritoneal, e se constitui no maior espaço extravascular pré-formado no corpo. Em um animal normal, a cavidade peritoneal é subatmosférica em pressão ( $-5 \mathrm{a}-8 \mathrm{~cm} \mathrm{H}_{2} \mathrm{O}$ ) e contém pequena quantidade de fluido (TRENT, 1995; DABAREINER, 1996; MURRAY, 1998).

Histologicamente, o peritônio é constituído por uma camada única de células mesoteliais, apoiadas em uma 


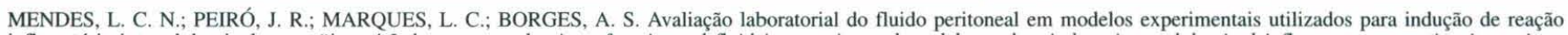

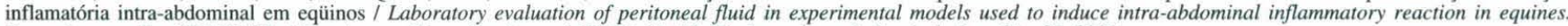
Rev. educ. contin. CRMV-SP / Continuous Education Journal CRMV-SP, São Paulo, volume 3, fascículo 3, p. 21 - $27,2000$.

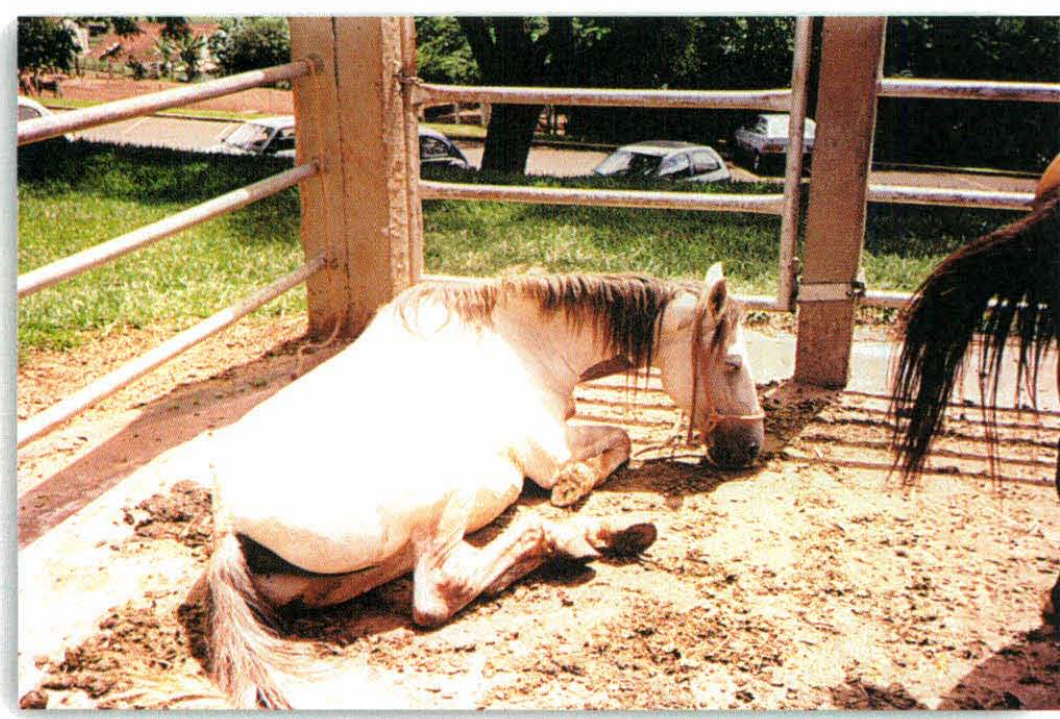

Figura 1. Eqüino com peritonite induzida experimentalmente pela inoculação intraperitoneal de E. coli - Depressão e decúbito.

lâmina basal fina, a qual está conectada a uma camada de tecido conectivo frouxo, contendo colágeno e fibras elásticas, que permitem um variado grau de movimentação. Esta camada de células funciona como uma barreira semipermeável à difusão de água e de solutos de baixo peso molecular entre o sangue e a cavidade abdominal. Para facilitar esta movimentação, o peritônio é coberto por uma fina camada de um filme seroso. (MURRAY, 1998).

O fluido peritoneal é um dializado de sangue com pH e conteúdo de eletrólitos semelhantes ao do plasma (BACH, 1973), sendo constantemente produzido e absorvido, e tendo como funções lubrificar a cavidade abdominal, inibir a formação de aderências, além de pequena propriedade antibacteriana. Na peritonite o movimento de fluido transperitoneal pode estar aumentado, causando uma rápida transudação de líquido que pode levar à hipotensão e ao choque hipovolêmico (TRENT, 1995).

Quando ocorre contaminação do peritônio, a primeira defesa é exercida pelo sistema linfático. As válvulas linfáticas do diafragma proporcionam uma limpeza unidirecional de debris do líquido peritoneal que são retirados pelo ducto torácico, enquanto que a defesa celular é exercida por macrófagos peritoneais, mastócitos e células mesoteliais. A presença de linfócitos $\mathrm{T}$ peritoneais ativados e produção local de anticorpos também foram demonstradas experimentalmente (DABAREINER, 1996).

Os macrófagos peritoneais possuem atividade antimicrobiana resultante de seus receptores para complemento, habilidade fagocítica e resposta imune mediada por células T. Além disso, os macrófagos peritoneais são importantes na quimiotaxia de neutrófilos e na estimula- ção de fibroblastos, os quais ajudam a localização de bactérias. As células mesoteliais peritoneais são fonte abundante de fator ativador de plasminogênio, o qual é responsável pela atividade fibrinolítica normal na superfície peritoneal (MURRAY, 1998).

\section{Fisiopatologia da injúria peritoneal}

A injúria peritoneal pode decorrer de qualquer insulto químico, mecânico ou infeccioso. A resposta inicial a um estímulo inflamatório é a liberação de histamina e serotonina, oriundos de mastócitos e macrófagos peritoneais, resultando em vasodilatação e aumento da permeabilidade vascular com transudação de plasma rico em fibrinogênio (TRENT, 1995; DABAREINER, 1996; MURRAY, 1998).

Macrófagos peritoneais estimulam a quimiotaxia a neutrófilos diretamente e, indiretamente, pela liberação do Fator de Necrose Tumoral (TNF) e Interleucina 1 (IL1). TNF e IL-1 estimulam a marginação e a degranulação de neutrófilos e alteram o endotélio vascular para promover aderência de leucócitos. As membranas celulares, em resposta a estes estímulos, produzem diversos subprodutos de fosfolipídeos, tais como o Fator Ativador de Plaquetas (PAF), prostaglandinas e leucotrienos, que contribuem para a resposta de vasodilatação. Dentro de horas, um influxo de fluido, proteína e neutrófilos ocorre na cavidade peritoneal em resposta ao estímulo inflamatório (TRENT, 1995; DABAREINER, 1996; MURRAY, 1998).

Transudação de opsoninas humorais, complemento e anticorpos, além de depressão na atividade fibrinolítica, com depósitos de fibrina sobre a superfície peritoneal e ileus mediado pelo sistema nervoso simpático também são observados na resposta inflamatória do peritônio. (TRENT, 1995).

As peritonites ocorrem secundariamente à contaminação por microrganismos, lesões vasculares envolvendo o trato gastrintestinal, trauma abdominal ou insultos químicos. Entretanto, a maioria dos casos são decorrentes de contaminações bacterianas. Isto pode ocorrer por via hematógena, perfuração de alças abdominais, desvitalização do intestino, abscedação ou de forma iatrogênica após enterotomia, enterocentese, trocaterização ou laparotomia (MURRAY, 1998). Não são raras as ocasiões em que ocorre uma convergência de causas, ou seja, o animal com afecção predisponente à peritonite é submetido à cirurgia em condições que exacerbam a predisposição existente ou mesmo lhe determinam a ocor- 


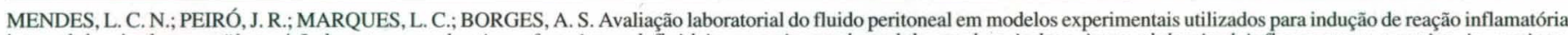

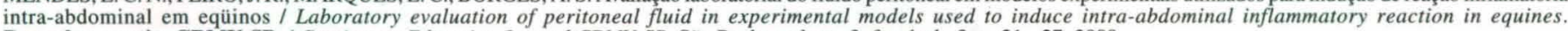
Rev. educ. contin. CRMV-SP / Continuous Education Journal CRMV-SP, São Paulo, volume 3, fascículo 3, p. 21 - 27, 2000.

rência (ALVES, 1997), mas os riscos serão maiores nos pacientes que necessitam de enterotomias ou enterectomias (BAXTER, 1992).

A resposta de caráter inflamatório beneficia o animal ao limitar o insulto, mas quando ocorre grande contaminação ou irritação peritoneal, esses processos são magnificados e começam a se tornar deletérios ao animal, resultando em hipovolemia, hipoproteinemia, ileus com distensão de alças, isquemia intestinal com subseqüente absorção de bactérias e toxinas e formação de abscessos e aderências. Além disto, respostas sistêmicas às toxinas bacterianas, principalmente os lipopolissacarídeos (LPS), podem comprometer a condição metabólica do paciente em virtude da grande liberação de mediadores inflamatórios, desencadeando o choque endotoxêmico (MURRAY, 1998).

Os sinais clínicos das peritonites dependem do processo primário, da extensão da inflamação e da causa, porém as peritonites sépticas geralmente desencadeiam sintomatologia clínica mais grave em virtude da liberação de mediadores inflamatórios em resposta às toxinas bacterianas. A maioria dos sinais clínicos são inespecíficos e incluem febre, depressão, inapetência, diminuição dos sons intestinais e desidratação (MURRAY, 1998).

Em peritonites induzidas experimentalmente, foi observado aumento da temperatura retal, taquicardia, sensibilidade e tensão da parede abdominal aumentados, diarréia, depressão e cianose ou palidez das mucosas aparentes (MENDES et al., 1999) (Figura 1).

\section{Modelos experimentais em eqüinos}

Recentemente no Brasil, vários modelos experimentais foram desenvolvidos com o objetivo de estudar diversas facetas da peritonite eqüina, principalmente aquelas relacionadas às complicações cirúrgicas da síndrome cólica. SUSKO et al. (1994) avaliaram o líquido peritoneal de eqüinos submetidos à obstrução experimental do jejuno e observaram aumentos dos números de hemácias, neutrófilos, teores de proteína total, fibrinogênio e glicose. Ainda verificaram aumento da atividade fagocitária de macrófagos e degeneração de neutrófilos.

MENDES (1996), avaliando a evolução das peritonites induzidas por $E$. coli, B. fragilis ou a associação dessas bactérias, observou leucopenia com linfocitose e neutropenia relativa em todos os animais ino- culados, nas primeiras seis horas após o início do experimento. Posteriormente, verificou-se em todos os animais leucocitose com neutrofilia. No líquido peritoneal ocorreram aumentos significativos do número de leucócitos, onde a maior contagem observada foi de $516 \times 10^{3}$ leucócitos por $\mathrm{mL}$, além de aumentos significativos dos teores de fibrinogênio $(1 \mathrm{~g} / \mathrm{dL})$ e de proteína total $(9,1 \mathrm{~g} \%)$. Os eqüinos inoculados com culturas puras de E. coli ou B. fragilis apresentaram peritonites brandas e autolimitantes, enquanto que os inoculados com a associação desses patógenos apresentaram sintomatologia clínica e alterações laboratoriais de maior intensidade e duração. Concluiu-se que a sintomatologia apresentada pelos animais (sensibilidade e tensão da parede abdominal, diarréia, diminuição dos sons intestinais e freqüência cardíaca), contagem de leucócitos no sangue e no líquido peritoneal, pressão arterial de $\mathrm{O}_{2}$ e os teores de fibrinogênio do líquido peritoneal foram os parâmetros que melhor demonstraram a evolução da doença, podendo ser utilizados na avaliação e no prognóstico de eqüinos com peritonite (Figura 2).

ALVES et al. (1996) estudaram parâmetros anatomopatológicos da localização e da freqüência da ocorrência de aderências, resultantes de peritonite induzida experimentalmente em eqüinos pela remoção de dois retalhos de peritônio (parietal e visceral) e pela deposição na cavidade abdominal de sangue total e de conteúdo do intestino grosso. Aproximadamente $32 \%$ dos animais vieram a óbito entre 3 e 34 dias após a cirurgia, e aqueles que morreram nos primeiros 15 dias apresentaram, à necropsia, peritonite fibrinosa difusa e toxemia. Aqueles que morreram mais tardiamente apresentaram aderências

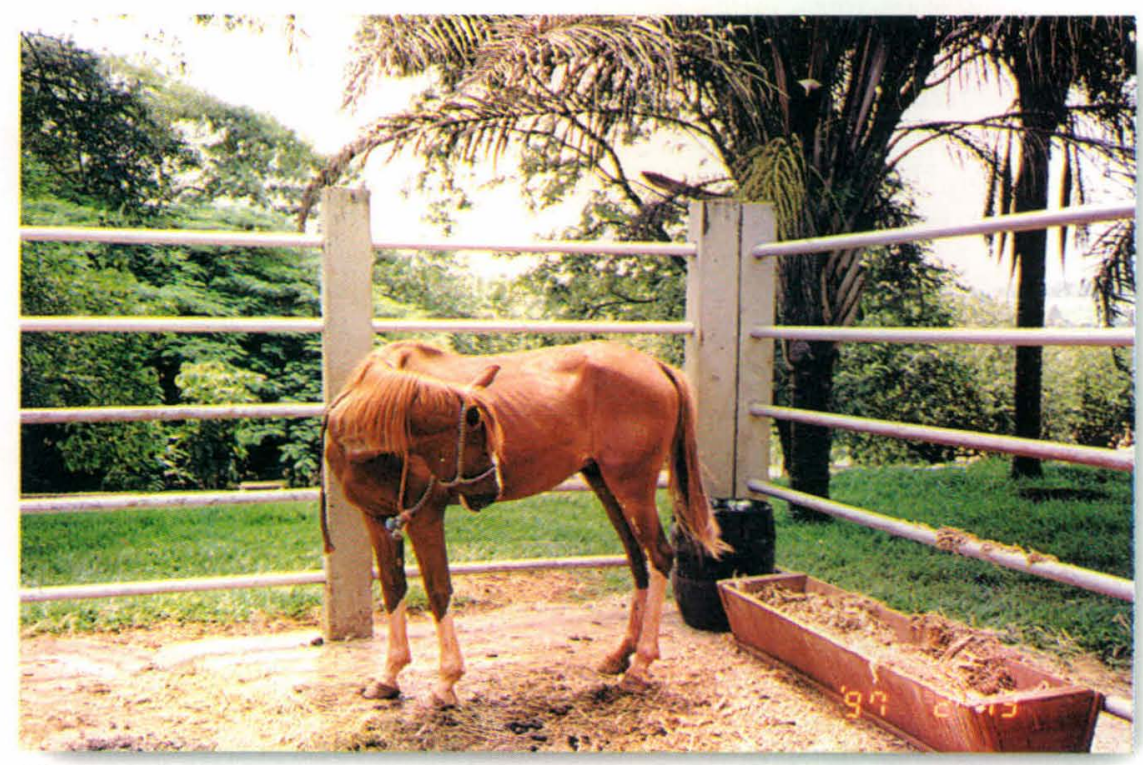

Figura 2. Eqüino com peritonite induzida experimentalmente pela inoculação intraperitoneal de E. coli - Olhar o flanco (dor abdominal). 


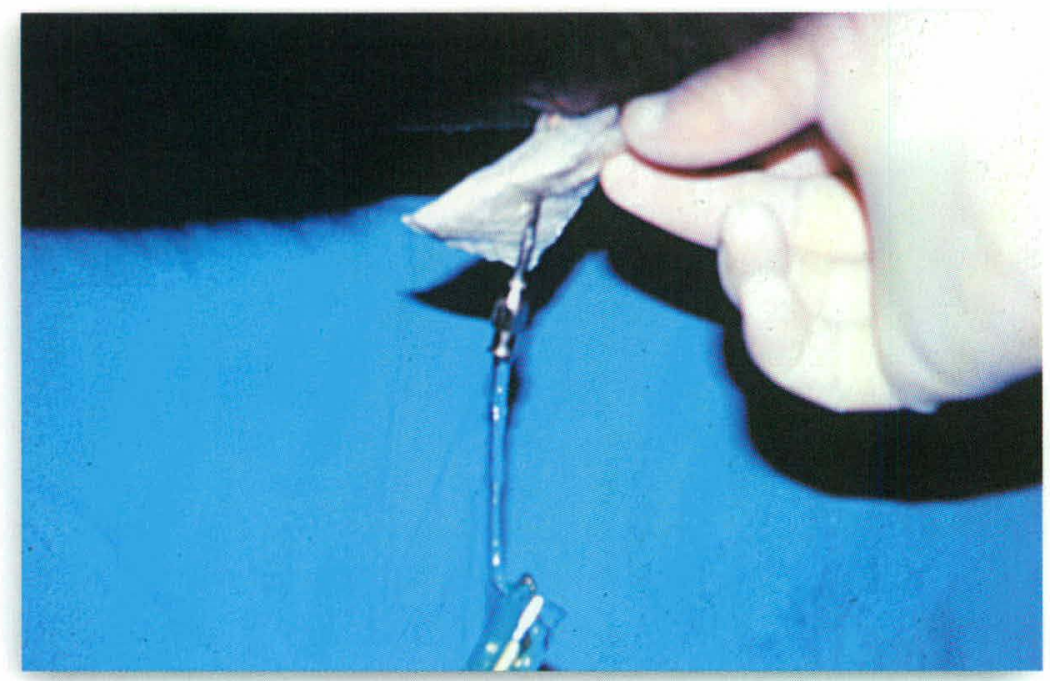

Figura 3. Coleta de líquido peritoneal com cânula mamária.

envolvendo segmentos do intestino delgado com distúrbios do trânsito gastroentérico. O grupo tratado com heparina, dimetilsulfóxido (DMSO) e enrofloxacina apresentou menor número de aderências.

A partir do mesmo modelo experimental descrito acima, CERQUEIRA et al. (1996) realizaram análise microbiológica de líquidos infundidos e recolhidos em diálises peritoneais e observaram a presença de bactérias em $100 \%$ dos líquidos dos animais controle e 50\% nos animais tratados (heparina, DMSO mais enrofloxacina). E. coli foi identificada em $97,2 \%$ e $100 \%$ das amostras dos grupos controle e tratado, respectivamente.

LOPES et al. (1999), pelo exame do líquido peritoneal e do hemograma, avaliaram a resposta do peritônio ao trauma cirúrgico e à aplicação de carboximetilcelulose, após abrasão da serosa e isquemia do jejuno por um período de 13 dias. Todos os animais desenvolveram inflamação peritoneal, sendo que no grupo tratado a inflamação foi mais intensa e ocorreu por um período mais longo. Observou-se ainda que a carboximetilcelulose foi fagocitada.

PEIRÓ et al. (1999) desenvolveram um modelo experimental de injúria peritoneal por inoculação de endotoxina na cavidade abdominal, e concluíram que a dose de $500 \mathrm{ng} / \mathrm{kg}$ de peso corporal produz quadro endotóxico semelhante ao da inoculação intravenosa.

\section{Análise do líquido peritoneal}

A avaliação físico-química e citológica do líquido peritoneal é um importante método auxiliar no diagnóstico das doenças abdominais nos eqüinos (MACKAY, 1992), sendo utilizada na diferenciação de peritonites sépticas e assépti- cas (BACH e RICKETTS, 1974; RICKETTS, 1987). A endotoxemia também é responsável por alterações neste líquido (VALADÃO et al., 1995).

A paracentese abdominal é considerada uma técnica invasiva de baixo risco, haja vista que, em 100 coletas realizadas, apenas em duas ocorreu perfuração de alça (SWANWICK e WILKINSON, 1976), e de 850 casos, estudados por TULLENERS (1983), apenas quatro apresentaram complicações, sendo duas celulites da parede abdominal e duas perfurações intestinais. Em condições normais, quando ocorre perfuração do intestino delgado, a lesão é rapidamente ocluída sem qualquer conseqüência para o animal. Complicações ocorrem quando a alça encontra-se distendida e desvitalizada (JUZWIAK et al., 1991).

SCHUMACHER et al. (1985) analisaram o fluido peritoneal de 15 eqüinos clinicamente sadios, submetidos a paracenteses abdominais diárias por um período de 5 dias, e não detectaram nenhuma alteração significativa nos constituintes do líquido peritoneal (densidade, número total e diferencial de monunucleares e de hemácias) (Figura 3).

Em um eqüino adulto sadio, a quantidade de líquido presente na cavidade abdominal varia de 100 a $300 \mathrm{ml}$ (PARRY e BROWNLOW, 1992). A colheita é influenciada pelo tipo de punção, alimentação, posição e repleção das alças intestinais e, principalmente, pelo grau de desidratação do animal, e em condições ideais, permite a colheita de 50 a $60 \mathrm{ml}$ de líquido peritoneal em um período de dez minutos aproximadamente (ALVES, 1997).

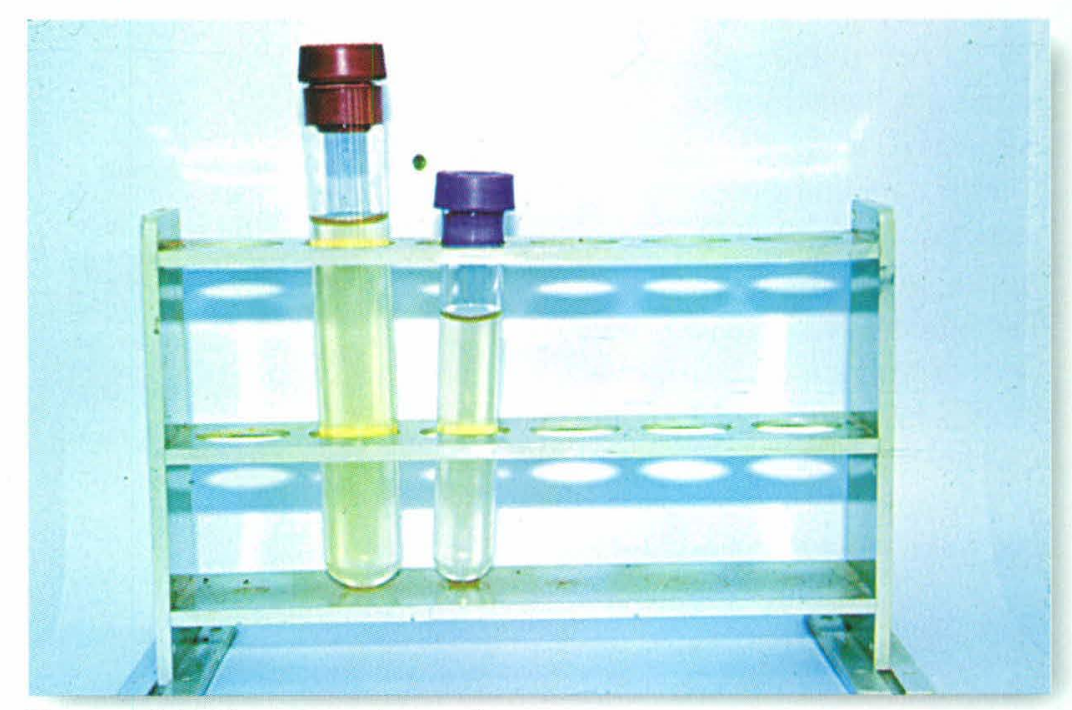

Figura 4. Líquido peritoneal normal. 


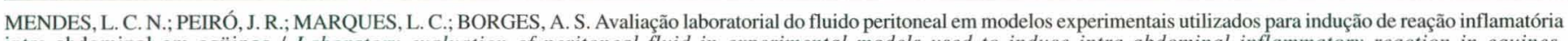

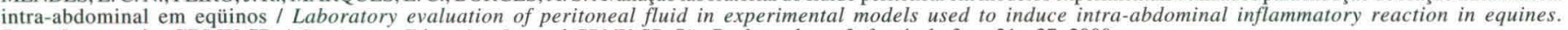
Rev. educ. contin. CRMV-SP / Continuous Education Journal CRMV-SP, São Paulo, volume 3, fascículo 3, p. 21 - $27,2000$.

Em condições normais, o líquido peritoneal é pálido, claro e contém teores de proteína inferiores a 2,5 g/ dL e contagem de células nucleadas menores que 5000 $\mathrm{ml}$. O líquido peritoneal torna-se turvo quando o número de células nucleadas e a taxa de proteína aumentam (RICKETTS, 1987; WILSON e GORDON, 1987; SPIER e SNYDER, 1992; MENDES, 1996; PEIRÓ, 1997) (Quadros 1 a 4) (Figura 4).

A distribuição de células polimorfonucleares (PMN) e mononucleares variam grandemente no líquido peritoneal normal, mas sempre com predominância dos PMN entre $24 \%$ a $60 \%$. A aparência das células à citologia deve ser normal apesar de alguns animais sadios apresentarem células mesoteliais ativadas (BROWNLOW et al., 1981; DABAREINER, 1996; MURRAY, 1998). Alterações qualitativas e quantitativas do líquido peritoneal foram observadas 12 horas após a instalação de peritonite experimental (FARIA et al., 1999).

O exame citológico do líquido peritoneal deve incluir colorações variadas como Wright e Gram, pois a morfologia das células do líquido peritoneal é importante no diagnóstico (Coloração de Wright) e a identificação de bactérias pelo método de Gram pode ser utilizada como parâmetro inicial de tratamento até que o cultivo e o antibiograma estejam prontos. O cultivo microbiológico deve ser feito para a identificação de aeróbios e anaeróbios, e o antibiograma deve ser executado com o intuito de orientar terapia antibiótica específica (DABAREINER, 1996). A análise do líquido peritoneal deve ser útil também para o acompanhamento da resposta à terapia, evidenciando alterações que ocorreram na cavidade abdominal (FARIA et al., 1999).

A resposta inicial à inflamação intraabdominal ou à oclusão vascular mesentérica é o extravasamento de proteína do plasma para o líquido peritoneal. Assim, o primeiro sinal de anormalidade é o aumento da taxa de proteína (PEIRÓ, 1997). Após cirurgia abdominal, castração ou parto, os teores de proteína e o número de células nucleadas encontram-se aumentados no líquido peritoneal (DABAREINER, 1996) (Quadro 5).

A concentração de fibrinogênio superior a $100 \mathrm{mg} / \mathrm{dL}$ no líquido peritoneal é indicador de processo inflamatório agudo (WILSON e GORDON, 1987) e foi considerado por MENDES (1996) como um pa-

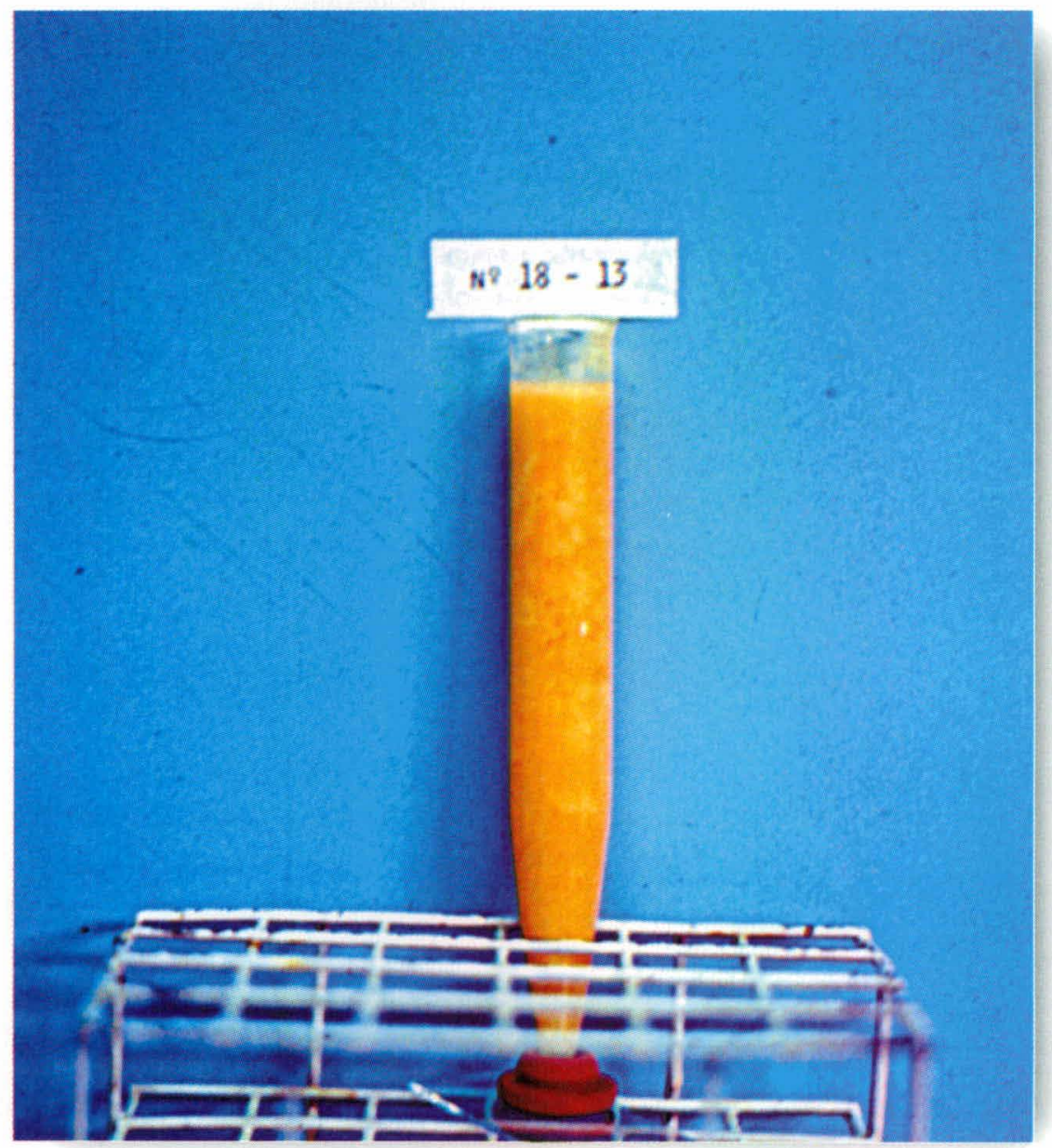

Figura 5. Líquido peritoneal com grande quantidade de leucócitos.

\section{Quadro 2. A cor é influenciada pela presença de carotenóides ou outros pigmentos, pelo conteúdo de proteína e de células, sendo normalmente amarelo-palha, variando de brilhante a opalescente.}

\begin{tabular}{|c|c|}
\hline \multicolumn{2}{|c|}{$\begin{array}{l}\text { Quadro 3. Odor: Sob condições } \\
\text { fisiológicas o líquido peritoneal é inodoro. }\end{array}$} \\
\hline \multicolumn{2}{|c|}{$\begin{array}{l}\text { Quadro 4. Densidade e } \mathrm{pH} \text { do } \\
\text { líquido peritoneal normal de eqüinos. }\end{array}$} \\
\hline Densidade específica: $1,008-1,093$ & $\mathrm{pH}: 7,25-7,40$ \\
\hline
\end{tabular}

râmetro importante no diagnóstico das peritonites por aumentar de forma aguda. Segundo HAWKINS et al. (1993), a avaliação do fibrinogênio plasmático é de baixo valor no estabelecimento do prognóstico das peritonites nos eqüinos (Quadro 6).

A lesão vascular progressiva faz com que as hemácias sejam extravasadas para a cavidade peritoneal e, 


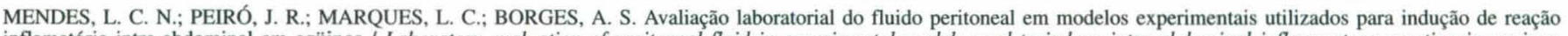
inflamatória intra-abdominal em eqüinos / Laboratory evaluation of peritoneal fluid in experimental models used to induce intra-abdominal inflammatory reaction in equines. Rev. educ. contin. CRMV-SP / Continuous Education Journal CRMV-SP, São Paulo, volume 3, fascículo 3, p. 21 - 27, 2000.

\begin{tabular}{|c|}
\hline $\begin{array}{c}\text { Quadro 5. A concentração de proteínas } \\
\text { no líquido peritoneal é menor que no sangue, } \\
\text { sendo a taxa albumina/globulina mais alta. }\end{array}$ \\
\hline
\end{tabular}

\begin{tabular}{|l|r|}
\hline \multicolumn{2}{|c|}{$\begin{array}{c}\text { Quadro 6. Teores de proteína e fibrinogênio do } \\
\text { líquido peritoneal normal de eqüinos. }\end{array}$} \\
\hline $\begin{array}{l}\text { Proteínas totais: }<2,5 \mathrm{~g} / \mathrm{dl} \\
\text { Globulinas } 0,7-1,4 \mathrm{~g} / \mathrm{dl}\end{array}$ & $\begin{array}{c}\text { Albumina } 0,3-1,0 \mathrm{~g} / \mathrm{dl} \\
\text { Fibrinogênio }<100 \mathrm{mg} / \mathrm{dl}\end{array}$ \\
\hline
\end{tabular}

Fontes: WILSON e GORDON, (1987); PARRY e BROWNLOW, (1992).

consequentemente, aumente a migração de leucócitos. O número total de leucócitos e a concentração de proteína também aumentam em eqüinos com abscessos peritoneais e peritonites (VALADÃO et al., 1995) (Figura 5).

Presença de líquido peritoneal muito claro (descolorido) indica diluição, e se presente em grande quantidade, sugere a possibilidade de ascite ou uroperitônio. Fluido serossanguinolento indica aumento no número de hemácias ou na quantidade de hemoglobina livre. Tal situação é verificada nos pacientes com degeneração intestinal e perda transmural de hemácias, nas punções do baço durante centeses, nas lacerações de vísceras abdominais ou quando ocorre contaminação do líquido peritoneal com sangue oriundo de vasos de pele ou da musculatura. Líquido esverdeado é resultado de enterocentese ou ruptura de alças intestinais, enquanto que líquido amarronzado está associado com estágio terminal de necrose tecidual (DABAREINER, 1996).

As atividades de algumas enzimas como a fosfatase alcalina, aspartato aminotransferase e desidrogenase láctica, quando aumentadas no líquido peritoneal de cavalos, podem refletir lesões em órgãos como o fígado, intestino e nos músculos (MAcKAY, 1992). O aumento da atividade da fosfatase alcalina no líquido peritoneal é dependente da desvitalização das camadas da parede do intestino delgado ou da liberação desta enzima pelos leucócitos granulócitos quando de uma irritação peritoneal (PEIRÓ, 1997). Apesar da creatina quinase poder ser encontrada em muitos tipos de células e possuir alta especificidade para a musculatura esquelética, acredita-se que esta enzima pode ser utilizada para aferir a intensidade do processo inflamatório peritoneal (WITTWER, 1988). Contudo, a importância clínica destas alterações na detecção de isquemia intestinal ou de outros órgãos é considerada limitada (Quadro 7).

Citocinas, como o TNF, IL-1, IL-6 e IL-10, produzidas por células presentes na cavidade abdominal, têm sido mensuradas experimentalmente nos processos de endotoxemia e isquemia em eqüinos (OGLE, et al. 1997; PEIRÓ, 1997). BARTON e COLLATOS (1999) observaram, em eqüinos com cólica, aumento significativo maior da IL6 no líquido peritoneal do que no plasma, mas a atividade desta citocina esteve mais aumentada naqueles animais com lesões inflamatórias ou estrangulantes do que naqueles com lesões não inflamatórias ou não estrangulantes. Atividade de TNF também foi detectada no líquido peritoneal destes eqüinos.

Quadro 7. Valores bioquímicos normais do líquido peritoneal de eqüinos.

\begin{tabular}{|l|l|}
\hline Glicose $74-203 \mathrm{mg} / \mathrm{dl}$ & Lactato $3,6-10,8 \mathrm{mg} / \mathrm{dl}$ \\
Uréia $10,9-23,2 \mathrm{mg} / \mathrm{dl}$ & Creatinina $1,8-2,7 \mathrm{mg} / \mathrm{dl}$ \\
Bilirrubina Total $0-1,2 \mathrm{mg} / \mathrm{dl}$ & Fosfatase Alcalina $0-161 \mathrm{UI} / 1$ \\
Desidrogenase láctica $0-355 \mathrm{UI} / \mathrm{l}$ & Aspartato aminotransferase $25-203 \mathrm{UI} / \mathrm{L}$ \\
Gama glutamiltransferase $0-6 \mathrm{UI} / \mathrm{l}$ & Fósforo inorgânico $1,2-7,4 \mathrm{mg} / \mathrm{dl}$ \\
\hline
\end{tabular}

Fonte: PARRY e BROWNLOW, (1992).

\section{SUMMARY}

This is a review article about the peritoneum anatomy and function, pathophysiology of the peritoneal injury, and evaluation of the normal peritoneal fluid. Normal values are compared to those obtained in experimental models of induced peritoneal inflammation that were developed in Brazil to study several aspects of peritonitis in horses, specially those associated with clinical and/or surgical complications of colic. It also discusses data related to cellularity, biochemical and anatomicopathological methods, as well as the quantitative evaluation of cytokines in the peritoneal fluid of these models.

Key words: experimental peritonitis, horses, peritoneal fluid, peritoneum, endotoxemia. 


\section{REFERÊNCIAS BIBLIOGRÁFICAS}

1 - ALVES, G.E.S. Tratamento da peritonite experimental em eqüinos com a associação de dimetilsulfóxido, heparina e enrofloxacina: Estudo clínico, cirúrgico e da patologia. Belo Horizonte, 1997. 177p. Tese (doutorado). Escola de Veterinária, UFMG.

2 - ALVES, G.E.S.; SANTOS, R.L.; FALEIROS, R.R.; MARQUES JUNIOR, A.P. Peritonite experimental em eqüinos: freqüência e localização de aderências. A Hora Veterinária, v.16, n.92, p.15-7, 1996.

3 - BACH, L.G. Exfoliative cytology of peritoneal fluid in the horse. Veterinary Annual. 1973, p.102-9.

4 - BACH, L.G.; RICKETTS, S.W. Paracentesis as an aid to the diagnosis of abdominal disease in the horse. Equine Veterinary Journal, v. 6, n. 3, p. 116-21, 1974.

5 - BARTON, M.H.; COLLATOS, C. Tumor necrosis factor and interleukin- 6 activity and endotoxin concentration in peritoneal fluid and blood of horses with acute abdominal disease. Journal Veterinary Internal Medicine, v.13, n.5 , p. 457-64, 1999.

6 - BAXTER, G.M. Recognizing and managing the postoperative complications of equine abdominal surgery. Veterinary Medicine, v.87, p.1113-20, 1992.

7 - BROWNLOW, M.A.; HUTCHINS, D.R.; JOHNSTON, K.G Reference values for equine peritoneal fluid. Equine Veterinary Journal, v.13, p.127-30, 1981.

8 - CERQUEIRA, M.M.O.P. C., ALVES, G.E.S., LIMA, L.A., MARQUES, A.P. Avaliação microbiológica de líquidos infundidos e recolhidos em diálises peritoneais de eqüinos com peritonite experimental. A Hora Veterinária, v. 16, n. 94, p. 11-2, 1996.

9 - DABAREINER, R.M. Peritonitis in horses In: SMITH, B.P. Large animal internal medicine, 2. ed., St Louis: Mosby Year Book, 1996, p. 742-9.

10 - FARIA, E.P.; MARQUES Jr. A.P.; ALVES, G.E.S. Características celulares e bioquímicas do líquido peritoneal de eqüinos submetidos à peritonite experimental. Arquivos Brasileiros de Veterinária e Zootecnia, v.51, n.4, p.335-44, 1999.

11 - HAWKINS, J.F.; BOWMAN, K.F.; ROBERTS, M.C.; COWEN, P. Peritonitis in horses: 67 cases (1985-1990) Journal of the American Veterinary Medical Association, v. 203, n.2, p. 284-8, 1993.

12 - JUZWIAK, J.S.; RAGLE, C.A.; BROWN, C,M.; KREHBIEL, J.D.; SLOCOMB,R,F. The effect of repeated abdominocentesis on peritoneal fluid constituents in the horse. Veterinary Research Compendiun, v.15, n.3, p. 177-80, 1991

13 - LOPES, M.A.F.; DEARO, A.C.O.; BIONDO, A.W.; GODIN, L.F.P.; IAMAGUTI, P.; THOMASSIAN, A.; KOHAYAGAWA, A. Exame do fluido peritoneal e hemograma de eqüinos submetidos à laparotomia e infusão intraperitoneal de carboximetilcelulose. Ciência Rural, v.29, n. 1, p. 79 $85,1999$.

14 - MAcKAY, R.J. Endotoxemia In: ROBINSON, N.E. Current therapy in equine medicine 3. ed., Philadelphia: W.B. Saunders, 1992, p. 225-32.

15 - MENDES, L.C.N. Estudo das alterações clínicas e laboratoriais de eqüinos portadores de peritonite experimental. Jaboticabal, 1996. 113p. Dissertação (Mestrado) UNESP, Faculdade de Ciências Agrárias e Veterinárias.

16 - MENDES, L.C.N.; MARQUES, L.C.; SCHOCKEN-ITURRINO, R.P.; AVILA, F.A. Clinical aspects of experimental peritonitis in horses. Ciência Rural, v.29, n 3, p. 493-97, 1999.
17 - MESSER, N.T. The use of laboratory tests in equine practice. Veterinary Clinical of North American. Equine Practice, v.11, p.345-9, 1995.

18 - MURRAY, M.J. Peritonitis. In: REED, S.M., BAYLY, W.M. Equine internal medicine. Philadelphia: W.B. Saunders, 1998, p. 700-5.

19 - OGLE, C.K.; GUO, X.; HASSELGREN, P.O.; OGLE, J.D.; ALEXANDER, J.W. The gut as a source of inflammatory cytokines after stimulation with endotoxin. European Journal Surgery, v. 163, n. 1, p. 45-51, 1997.

20 - PARRY, B.W.; BROWNLOW, M.A. Peritoneal fluid. In: COWELL R.L., TYLER, R.D. Cytology and hematology of the horse. St. Louis: Mosby, 1992. p.121-51.

21 - PEIRÓ, J.R. Endotoxemia experimental em eqüinos: avaliação clínico-laboratorial. Jaboticabal, 1997. 89p. Dissertação (Mestrado), Faculdade de Ciências Agrárias e Veterinária, UNESP.

22 - PEIRÓ, J.R.; CAMPEBELL, R.C.; SANTANA, A.E.; VALADÃO, C.A.A. Clinical and laboratory evaluation after intraperitoneal injection of lipopolysaccharide (LPS). Journal Equine Veterinary Science, v.19, n. 3, p. 187-91, 1999.

23 - RICKETTS, S.W. Peritonitis In: ROBINSON, N.E. Current therapy in equine medicine. 2 . ed., Philadelphia: W. B. Saunders, 1987. p. 79-81.

24 - SCHUMACHER, J.; SPANO, J.S.; MOLL, H.D. Effects of enterocentesis on peritoneal fluid constituents in the horse. Journal of the American Veterinary Medical Association, v. 186, n. 12, p. 1301-3, 1985.

25 - SPIER, S.J.; SNYDER, J.R. Physical and laboratory evaluations of the horse with colic. In: ROBINSON, N.E. Current therapy in equine medicine. 3. ed., Philadelphia: W.B. Saunders, 1992. p.193.

26 - SUSKO, I.; GANDOLFI, W; KOHAYAGAWA, A.; THOMASSIAN, A. Avaliação do líquido peritoneal de eqüinos submetidos à obstrução experimental do intestino delgado. Agrárias, v.13, n. 1-2, p. 49-54, 1994.

27 - SWANWICK, R.A.; WILKINSON, J.S. A clinical evaluation of abdominal paracentesis in the horse. Australian Veterinary Journal, v. 52, p. 109-17, 1976.

28. TRENT, A.M. The peritoneum and peritoneal cavity. In: KOBLUK, C.N. et al. The horse diseases \& clinical management. Philadelphia: Saunders, 1995. p.373-404.

29 - TULLENERS, E.P. Complications of abdominocentesis in the horse. Journal of the American Veterinary Medical Association, v. 182, n.3, 232-4, 1983.

30 - VALADÃO, C.A.A.; PEIRÓ, J.R.; SANTANA, A.E.; BECHARA, G.H. Evaluation of peritoneal fluid in horses with experimental endotoxemia. Journal Equine Veterinary Science, v. 15, n. 3, p. 124-8, 1995.

31 - WILSON, J.; GORDON, B. Equine colic: interpreting the diagnostic tests. Veterinary Medicine, v.82, n. 6, p. $629-45,1987$

32 - WITTWER, F. La paracentesis como ayuda al. diagnostico de alteraciones digestivas en eqüinos In: ARAYA, O. Enfermidades de los eqüinos: algunas patologias internas y su tratamiento. Santiago, s.n., 1988. p. 496-505. 